\title{
AVALIAÇÃo FORMATIVA NA PRODUÇÃo ORAL: ANÁLISE DE UMA EX- PERIÊNCIA EM UM CURSO DE PORTUGUÊS LÍNGUA ESTRANGEIRA
}

FERNANDa SOUZA E SILVA*

Myriam Crestian Chaves da CUNHA ${ }^{* *}$

\section{RESUMO}

Este trabalho investiga o impacto de procedimentos de avaliação formativa no desenvolvimento da competência de produção oral em aprendentes de Português Língua Estrangeira. Buscou-se averiguar, por meio de questionários e entrevistas, de que maneira a apropriação dos critérios de avaliação da produção oral usados no exame do Certificado de Proficiência da Língua Portuguesa contribui para o desenvolvimento dessa habilidade em alunos preparandose para o exame. Os resultados da pesquisa-ação aqui analisada revelam que as ações implementadas possibilitaram não só práticas autoavaliativas mais condizentes com cada critério, como também a autorregulação de métodos e estratégias de aprendizagem, levando os estudantes a um melhor nível de preparação para o exame.

PALAVRAS-CHAVE: avaliação formativa, autorregulação da aprendizagem, produção oral, Português Língua Estrangeira, exame Celpe-Bras.

\section{INTRODUÇÃO}

No âmbito da internacionalização das Instituições de Ensino Superior brasileiras, assistimos, durante as últimas décadas, ao aumento de programas de mobilidade estudantil como o Programa de Estudantes-Convênio de Graduação (PEC-G), cujo público, aprendente de Português, é nosso foco neste artigo. Esse programa é apresentado

* Mestre em Letras/Linguística pela Universidade Federal do Pará (UFPA), Belém, Pará, Brasil. Graduação em Letras - Hab Língua Francesa/(UFPA), Belém, Pará, Brasil. E-mail : f.souza.fr@gmail.com.

** Doutorado em Ciências da Linguagem pela Universidade de Toulouse II (Le Mirail), França. Mestrado em Letras - Lingüística - pela Universidade Federal do Pará (UFPA), Belém, Pará, Brasil. E-mail : mycunha@gmail.com. 
da seguinte forma, no site do Ministério das Relações Exteriores, que o gerencia junto com o Ministério da Educação e em parceria com as IES brasileiras:

O Programa de Estudantes-Convênio de Graduação (PEC-G) [...] oferece a estudantes de países em desenvolvimento com os quais o Brasil mantém acordo educacional, cultural ou científico-tecnológico a oportunidade de realizar seus estudos de graduação em Instituições de Ensino Superior (IES) brasileiras. (BRASIL, s/d.).

Para cursarem a graduação, os candidatos ao referido programa, que são jovens entre 18 e 25 anos, precisam obter o Certificado de Proficiência em Língua Portuguesa para Estrangeiros (Celpe-Bras), pelo menos em nível intermediário. Caso não haja postos aplicadores do referido exame em seu país de origem, os candidatos podem se preparar ao exame em um dos cursos de Português para Estrangeiros (PLE) oferecidos pelas instituições de ensino participantes do programa. Entre esses cursos encontra-se o da Universidade Federal do Pará (denominado aqui de Curso Pré-PEC-G), no âmbito do qual foi desenvolvido o estudo aqui relatado.

O Curso Pré-PEC-G é oferecido na modalidade presencial, em ritmo intensivo, com 20 horas de aulas semanais em um total de 36 semanas, durante os oito meses compreendidos entre a chegada desses estudantes e o momento em que eles prestam o exame Celpe-Bras.

Com frequência, mesmo após meses de estudo intensivo de português e embora já sejam capazes de se comunicar de forma razoável no cotidiano, os alunos ainda sentem dificuldades na habilidade oral em situações em que tenham que expor mais demoradamente opiniões a respeito de determinado assunto. Com base em observações de aula realizadas na turma PEC-G/2014, nas quais se percebeu, entre outros, que os aprendentes, em sua maioria, avaliavam a sua produção oral tendo como único critério o domínio da gramática, compreendemos que a conscientização a respeito dos outros critérios de avaliação do exame Celpe-Bras e a apropriação desses critérios eram decisivas para a autoavaliação e para a consequente autorregulação da expressão oral dos aprendentes.

Para alcançar esses objetivos de aprendizagem, foram promovidas, nas aulas, atividades de reflexão metacognitiva que serão aqui analisadas. Pretendemos, com este estudo, contribuir para o 
desenvolvimento de práticas de avaliação formativa e de efetiva (auto) (r)regulação da aprendizagem na produção oral em aulas de português como língua estrangeira. Apresentamos, a seguir, a fundamentação teórica relativa à avaliação formativa e a seus procedimentos, bem como as bases documentais sobre a avaliação da parte oral no exame Celpe-Bras e a metodologia adotada em nossa pesquisa.

\section{AVALIAÇÃO FORMATIVA}

A discussão acerca da avaliação formativa não é recente. Quando a modalidade foi proposta na década de 1960, distinguindo-se da modalidade somativa, a avaliação formativa era pensada na perspectiva do behaviorismo dominante, atribuindo ao professor o papel central no processo de avaliação e de regulação (ALLAL, 1989). Embora as decisões fossem tomadas em prol do aluno, todos os procedimentos, desde a coleta de informações até a escolha das medidas ditas "corretivas", eram tarefas exclusivas do docente. Com o advento da psicologia cognitiva, que levou, na didática das línguas, a preconizar a chamada "centração no sujeito aprendente", esse modelo de avaliação formativa começou a ser questionado (BONNIOL; VIAL, 1997).

A partir de então, como lembram Huver e Springer (2011, p. 19), o campo da avaliação passou a opor dois paradigmas epistemológicos: o mecanicista, que encara a avaliação de forma quantitativa e objetiva, e o holístico, "no qual a avaliação é percebida como fundamentalmente subjetiva, situada, hermenêutica". Nesse último, os atores da avaliação pedagógica (professores e alunos) passam a adotar "uma postura esclarecida, problematizada e, portanto, reflexiva". Em decorrência da visão holística, assistimos ao surgimento de uma multiplicidade de propostas, todas elas variantes da avaliação formativa, em oposição à avaliação formativa de inspiração behaviorista (MELO, 2009). No entanto, essa diversidade de reformulações não foi acompanhada de um referencial, nem teórico nem prático, sólido o suficiente para que uma avaliação realmente "a serviço da aprendizagem" (PERRENOUD, 1998) fosse implementada.

A constatação da necessidade de um quadro teórico que oriente a ação dos professores e a conclusão de que as múltiplas variantes ditas formativas da avaliação compartilhavam dos mesmos propósitos e se 
inspiravam em concepções cognitivistas da aprendizagem estão na origem da expressão Avalição Formativa Alternativall (AFA), proposta por Fernandes (2006). O autor justifica o uso das designações formativa e alternativa pelo fato de elas evidenciarem duas características fundamentais:

a) o fato de estarmos a lidar com uma avaliação cuja principal função é a de melhorar e regular as aprendizagens e o ensino e que, por isso, é necessária para o desenvolvimento dos sistemas educativos (avaliação formativa); e b) o fato de estarmos perante uma avaliação formativa que é alternativa à avaliação formativa de inspiração behaviorista e a todo o espectro de avaliações mais ou menos indiferenciadas ditas de intenção ou de vontade formativa (avaliação alternativa). (FERNANDES, 2006, p. 25-26).

A AFA tem como base os contributos de duas correntes teóricas muito fortes no âmbito dos estudos acerca da avaliação formativa: a corrente anglo-saxônica e a corrente francófona (FERNANDES, 2008). Abordando a avaliação formativa de maneira mais pragmática, a tradição anglo-saxônica considera o feedback como princípio norteador, decisivo para a melhoria das aprendizagens. Nessa perspectiva teórica, são enfatizados os mecanismos de regulação da interação pedagógica, através dos quais o professor, a partir dofeedback dado aos aprendentes, poderá orientá-los de modo a melhorarem a sua aprendizagem.

Para a tradição francófona, a avaliação formativa é considerada uma fonte de regulação dos processos tanto de ensino como de aprendizagem, o que faz dos processos regulatórios a chave da aprendizagem. O cerne da avaliação está na observação metódica dos aprendentes, para que, com base na análise das informações coletadas, o professor possa intervir, lançando mão de uma avaliação formativa que os ajude a regular autonomamente a aprendizagem (FERNANDES, 2008, p. 352). Mas essa regulação tem por objetivo, in fine, a apropriação dos critérios de avaliação pelo aprendente, que se traduza em efetiva autoavaliação e autorregulação (NUNZIATI, 1990).

Allal e Michel (1993) ressaltam que toda intervenção avaliativa do professor, mesmo não tendo objetivos formativos, incide sobre a atividade autoavaliativa dos aprendentes. Levando-se em conta que toda avaliação realizada pelo professor está inserida em um contexto mais 
global de regulação, seja do dispositivo didático, seja das atividades de formação, essas autoras reconhecem a dificuldade de se diferenciar claramente estes dois construtos: autoavaliação e autorregulação. Por isso, definem a autoavaliação situando-a:

[...] no conjunto de condutas autorregulatórias do aluno, aquelas que estão diretamente ligadas às dimensões avaliativas de uma situação didática, ou seja, aquelas que dizem respeito aos objetivos pedagógicos visados, às performances e produtos exigidos, aos critérios de apreciação valorizados pelo professor, pela instituição, pela cultura ao redor. (ALLAL; MICHEL, 1993, p. 240).

Como lembra Hoffmann (2005), a (auto)avaliação é uma capacidade inerente às atividades humanas, uma vez que processos (auto)avaliativos, embora geralmente inconscientes, estão presentes em todas as nossas ações. No que tange à aprendizagem, a autoavaliação ganha status de "competência primordial a ser construída" (NUNZIATI, 1990, p. 58), com o intuito de permitir ao aluno "passar de um simples "savoir faire não refletido, puramente operatório, para chegar a um savoir faire refletido graças ao qual ele pode intervir e agir conscientemente" (CARDINET apud PILLONEL; ROUILLER, 2002, p. 30).

Nessa perspectiva, faz-se então necessário ensinar aos alunos a se autoavaliar, através de atividades de reflexão e da utilização de estratégias de autoavaliação, ${ }^{1}$ por meio das quais os alunos poderão se tornar conscientes não só de suas capacidades, de seus processos e atitudes no tocante à atividade linguageira (no nosso caso), mas também das qualidades apresentadas ou não pelas suas produções. Para isso, o aluno precisa estar consciente dos critérios que sua produção deve atender e "devem ser levados a utilizá-los em um certo número de situações, de exercícios propostos pelo docente" (GENTHON apud BONNIOL; VIAL, 1997, p. 247). No entanto, Nunziati reconhece a dificuldade que é construir exercícios de apropriação de critérios:

Não é simples. Comunicar os critérios de avaliação aos alunos antes da execução da tarefa já é eficaz. Mas não é eficiente quando visamos objetivos de transferência. Enquanto noção instrumental o critério exige uma construção ativa pelo aprendente [...] A atividade de apropriação é essencialmente um exercício de verbalização para si e 
para os outros do funcionamento das tarefas. [...]. De maneira geral o professor deveria encarregar o aluno de descrever os procedimentos experimentados com o conjunto da turma e de esclarecer a situação em relação aos objetivos anunciados. (NUNZIATI, 1990, p. 63).

Em outras palavras, enquanto na avaliação formativa de inspiração behaviorista cabia ao professor definir os critérios de avaliação e aos alunos se situarem em face desses critérios, com a avaliação formativa alternativa estes passam a ser construídos em sala de aula, em conjunto com os alunos, e as situações de avaliação se tornam resultado de um grande envolvimento aluno-professor, configurando-se como situações de efetiva responsabilidade e emancipação (FERNANDES, 2008).

Com base nessas concepções teóricas, divulgadas há bastante tempo, porém raramente transformadas em práticas efetivas, no contexto escolar brasileiro, o estímulo à aprendizagem da regulação foi proposto como passo primordial, na aprendizagem dos alunos da turma Pré-PEC-G. Isso foi realizado, em sala de aula, por intermédio de ações que visassem ao fomento da competência autoavaliativa dos aprendentes. Tratava-se, como resume Grego (2013, p. 102), de leválos "através de autoquestionamento, [a] perceber e atribuir significado" àquilo que produzem, de modo a adquirirem um olhar mais crítico tanto sobre suas próprias produções quanto sobre os métodos e estratégias dos quais lançam mão no processo de aprendizagem no âmbito do desenvolvimento da expressão oral, que será abordada a seguir.

\section{O EXAMe Celpe-Bras - PARTE ORAL}

O exame Celpe-Bras foi criado em 1993 para suprir a necessidade de um teste que legitimasse a proficiência de estrangeiros precisando integrar-se à sociedade brasileira ou usar o português do Brasil no exterior (MOUTINHO; VIANA, 2011). Para Scaramucci (2004, apud MOUTINHO; VIANA, 2011), o Celpe-Bras é um exame de alta relevância, uma vez que seus resultados podem orientar decisões importantes referentes aos candidatos que a ele se submetem. Como exemplo dessas situações, temos a exigência desse certificado para o ingresso de estudantes estrangeiros em universidades brasileiras no âmbito do programa Pré-PEC-G. 
Composto de tarefas que avaliam de forma integrada as quatro competências - compreensão oral e escrita, produção oral e escrita -, o exame é estruturado em duas partes: uma coletiva e outra individual. $\mathrm{Na}$ parte coletiva, que avalia as competências de compreensão oral, compreensão escrita e produção oral, os candidatos precisam produzir, em um período de três horas, quatro tarefas com propósitos e interlocutores específicos, com base em informações retiradas, respectivamente, de um vídeo, de um áudio e de dois textos.

A parte oral, que é abordada de maneira mais aprofundada neste trabalho, consiste em uma entrevista de 20 minutos, na qual o candidato e o entrevistador/avaliador, acompanhados por um observador/avaliador, conversam, inicialmente, acerca de informações pessoais do candidato. No restante da entrevista, a interação entrevistador-examinando toma por base, sucessivamente, três elementos provocadores ${ }^{2}$ diferentes, que têm por objetivo facilitar o desenvolvimento da interação oral acerca de tópicos do cotidiano e de interesse geral do candidato (INEP, 2003).

No âmbito do curso de PLE preparatório para o Celpe-Bras ofertado pela UFPA, considerando as necessidades dos alunos, que na maioria das vezes pouco - ou nunca - tiveram contato com o português e com exames tendo características como as do CelpeBras, é preciso dedicar atividades à preparação específica para cada parte do exame. Atuando desde 2013 nessa preparação, constatamos, a partir de observações do desempenho dos alunos e da aplicação de questionários, que, mesmo após meses de aulas intensivas com uma metodologia comunicativa, os alunos ainda apresentam dificuldades na habilidade oral, motivada, entre outros: a) pelo fato de os alunos, a partir do momento em que conseguem se comunicar em português em sua vida cotidiana, considerarem que já atingiram o nível de proficiência necessário para o exame, deixando assim de envidar maiores esforços em sua preparação; b) por avaliarem a sua produção oral tendo como único critério o domínio da gramática.

Levando-se em conta que, de acordo com o manual do candidato (INEP, 2003, p.15), a parte oral é avaliada segundo os critérios indicados no Quadro 1, compreendemos que a apropriação desses outros critérios (além do critério da correção gramatical) é decisiva para o desenvolvimento reflexivo e a autorregulação da expressão oral dos aprendentes. 
QUadro 1 - CRitérios de aVAliaÇão da PARTE ORAL

\begin{tabular}{|c|c|c|}
\hline Competência & Critério & Indicador \\
\hline Compreensão & $\begin{array}{l}\text { Compreensão do fluxo } \\
\text { natural da conversação }\end{array}$ & $\begin{array}{l}\text { dispensa de repetições ou de } \\
\text { reformulações }\end{array}$ \\
\hline \multirow{8}{*}{ Produção } & \multirow{4}{*}{$\begin{array}{l}\text { Recursos interacionais e } \\
\text { estratégicos }\end{array}$} & $\begin{array}{l}\text { contribuição para o } \\
\text { desenvolvimento da conversa }\end{array}$ \\
\hline & & flexibilidade na mudança de tópico \\
\hline & & uso de estratégias comunicativas \\
\hline & & adequação ao interlocutor \\
\hline & Fluência & manutenção do fluxo da conversa \\
\hline & Pronúncia & $\begin{array}{l}\text { adequação na pronúncia, no ritmo } \\
\text { e na entonação }\end{array}$ \\
\hline & Gramática & $\begin{array}{l}\text { variedade e adequação no uso de } \\
\text { estruturas linguísticas }\end{array}$ \\
\hline & Léxico & $\begin{array}{l}\text { extensão e adequação no uso do } \\
\text { vocabulário }\end{array}$ \\
\hline
\end{tabular}

Fonte: Elaboração própria ( 2017)

À luz das abordagens pós-comunicativas de ensino de línguas estrangeiras, que primam pela implicação ativa do aprendente no processo de aprendizagem, bem como à luz das concepções de avaliação formativa que expusemos na primeira parte, o desenvolvimento da reflexividade do aprendente aparece como fundamental para a formação de um falante competente. Ao propor situações de aprendizagem que permitam apropriar-se de critérios, estabelecer objetivos, planificar e avaliar sua aprendizagem, o professor promove momentos de reflexão metacognitiva indispensáveis para o desenvolvimento das competências autoavaliativas do aluno e, portanto, de suas habilidades orais. Este, por sua parte, ao distanciar-se desse processo, objetiva-o, podendo agir sobre ele e efetuar modificações, caso necessário, em outras palavras, autorregular-se.

As questões acima justificam que sejam ampliadas as investigações referentes aos processos formativos no âmbito do ensino/ aprendizagem de línguas estrangeiras, com ênfase nos processos de regulação e autorregulação das habilidades linguageiras, visto que eles 
envolvem conhecimentos de domínio teórico diversos, ainda escassos nessa área, principalmente, na parte oral (LEROY, 2014).

Nessa perspectiva, ao longo do ano de 2015, foi realizada uma experiência de identificação de necessidades e elaboração de atividades visando ao desenvolvimento das capacidades autoavaliativas $\mathrm{e}$ autorregulativas dos aprendentes, as quais foram experimentadas junto a uma turma de 12 alunos do Curso Pré-PEC-G. O presente trabalho, que será descrito na próxima seção, pretende dar continuidade a esse estudo, sistematizando e interpretando os numerosos dados então constituídos.

\section{Metodologia}

Aliando pesquisa e prática, de acordo com Engel (2000), a pesquisa-ação busca desenvolver conhecimento e compreensão de fenômenos ligados ao processo de ensino/aprendizagem no curso dos acontecimentos. Segundo o autor, a pesquisa-ação configura-se como "um meio de desenvolvimento profissional de 'dentro para fora', pois, parte das preocupações e interesses das pessoas envolvidas na prática, envolvendo-as em seu próprio desenvolvimento profissional" (ENGEL, 2000, p. 183).

Uma das características da pesquisa-ação é o seu caráter cíclico, uma vez que suas fases são planejadas para sanar problemas diagnosticados em fases anteriores. Sendo assim, configura-se como uma modalidade de pesquisa de cunho autoavaliativo, pois permite que as intervenções realizadas no processo sejam constantemente avaliadas e o feedback obtido seja "traduzido em modificações, mudanças de direção e redefinições, conforme necessário, trazendo benefícios para o próprio processo, isto é, para a prática" (ENGEL, 2000, p. 185). Foi essa lógica autoavaliativa e autorregulatória que motivou este estudo, visando, entre outros, dar continuidade ao estudo realizado em 2015, cujos contexto e corpus serão apresentados a seguir.

\section{CoNTEXTO DA PESQUISA}

O estudo teve como lócus o curso de Português como Língua Estrangeira ofertado aos candidatos ao programa PEC-G da 
Universidade Federal do Pará. Durante as 36 semanas de aula, isto é, de sua chegada ao Brasil até o momento em que se submetem ao exame Celpe-Bras, os alunos dessa turma têm aulas de segunda a sexta, das 14:30 às 18:00 horas. Em geral, depois de dois meses de aula, dois dias na semana são dedicados à preparação específica das partes escrita e oral do referido exame. A intervenção aqui analisada ocorreu de maio a setembro de 2015 junto a 12 alunos $^{3}$ do Curso Pré-PEC-G.

\section{ETAPAS DA PESQUISA-AÇÃO}

A pesquisa ${ }^{4}$ foi planejada em dois módulos, conforme sintetizado no Quadro 2: um de compreensão dos critérios e outro de desenvolvimento das competências orais em vista daqueles critérios. Com o objetivo de conhecer os impactos das atividades, foram aplicados questionários no início e ao fim da intervenção. O questionário inicial era composto de três perguntas que visavam levar o aluno a autoavaliar o seu desempenho na produção oral, justificar sua apreciação e explicitar as atividades que realizava fora de sala de aula para praticar essa competência. Essas questões foram retomadas no questionário final, que também contava com mais três perguntas sobre o impacto dos instrumentos e procedimentos utilizados durante o semestre.

Durante a primeira etapa, várias atividades de construção de critérios de avaliação da produção oral foram realizadas em sala, em conjunto com os alunos. Com base nas discussões propostas em torno de temas que aparecem frequentemente nos elementos provocadores do Celpe-Bras, a turma refletiu sobre as características esperadas da performance dos candidatos durante uma entrevista. Construiu-se, assim, uma compreensão dos critérios de avaliação usados no exame.

Além disso, também foram realizados dois tipos de tarefas (avaliação mútua e seminários), visando à apropriação dos critérios. Nas primeiras, os alunos, divididos em grupos, recebiam grades de avaliação e elementos provocadores para realizarem minientrevistas nos moldes do Celpe-Bras. Durante a atividade, os alunos se revezavam nos papéis de entrevistado, entrevistador e observador. Os resultados das avaliações eram, em seguida, discutidos pelo grupo. Já nos seminários, os alunos deviam apresentar a seus colegas exposições orais referentes 
a temas variados. Durante a apresentação, eles eram avaliados por toda a turma, com base na ficha de avaliação do Celpe-Bras. Ao fim das apresentações, cada aluno recebia as fichas preenchidas pelos pares.

QUAdro 2 - OrganizaÇão do trabalho DURANTE A PESQUiSa-AÇÃo

\begin{tabular}{|c|c|c|c|}
\hline Período & Etapas & Atividades & Objetivo \\
\hline \multirow{3}{*}{$\begin{array}{l}\text { maio a } \\
\text { julho de } \\
2015\end{array}$} & \multirow{3}{*}{$\begin{array}{l}\text { I. Compreensão } \\
\text { dos critérios }\end{array}$} & $\begin{array}{l}\text { - Definição e } \\
\text { discussão dos } \\
\text { critérios. }\end{array}$ & $\begin{array}{l}\text { Construção dos } \\
\text { critérios. }\end{array}$ \\
\hline & & $\begin{array}{l}\text { - Avaliação mútua } \\
\text { de minientrevista. }\end{array}$ & \multirow{2}{*}{$\begin{array}{l}\text { Apropriação dos } \\
\text { critérios para } \\
\text { a avaliação e a } \\
\text { autoavaliação das } \\
\text { produções orais. }\end{array}$} \\
\hline & & $\begin{array}{l}\text { - Seminários } \\
\text { com avaliação do } \\
\text { expositor pelos } \\
\text { colegas. }\end{array}$ & \\
\hline \multirow{2}{*}{$\begin{array}{l}\text { agosto e } \\
\text { setembro } \\
\text { de } 2015\end{array}$} & \multirow{2}{*}{$\begin{array}{l}\text { II. } \\
\text { Desenvolvimento } \\
\text { das habilidades } \\
\text { orais }\end{array}$} & $\begin{array}{l}\text { - Realização de } \\
\text { quatro simulados de } \\
\text { entrevistas Celpe- } \\
\text { Bras com avaliação } \\
\text { externa. }\end{array}$ & $\begin{array}{l}\text { Uso dos critérios para } \\
\text { a autorregulação das } \\
\text { produções orais. }\end{array}$ \\
\hline & & $\begin{array}{l}\text { - Explicitação } \\
\text { de estratégias de } \\
\text { aprendizagem. }\end{array}$ & $\begin{array}{l}\text { Regulação de hábitos } \\
\text { e estratégias de estudo } \\
\text { em relação à oral. }\end{array}$ \\
\hline
\end{tabular}

Fonte: Elaboração própria ( 2017)

Ao longo da segunda etapa, foram realizados quatro simulados com a professora da turma desempenhando o papel de avaliador externo, nos quais foram utilizados elementos provocadores de sessões anteriores do exame. As entrevistas, por sua vez, também se desenrolavam em duas etapas: a) um simulado (20 minutos) durante o qual a pesquisadora pontuava a performance do aluno, utilizando a grade de avaliação do Celpe-Bras; b) uma discussão a respeito do desempenho no simulado 
e das atividades de produção oral (10 minutos). Nesse momento, os alunos recebiam o feedback individual de sua produção e autoavaliavam sua performance, tanto no simulado quanto nas aulas, e as atividades que realizavam fora de sala de aula para se preparar para a parte oral do exame.

Também foram propostas atividades de reflexão sobre as estratégias de aprendizagem que os aprendentes usavam ou poderiam usar, explicitando com eles como atividades de exposição à língua poderiam se tornar produtivas para alcançar os novos objetivos que a compreensão dos critérios revelavam a seus olhos.

\section{O CORPUS}

O corpus deste trabalho é constituído por: a) questionários inicial e final, compostos de questões abertas e fechadas sobre a avaliação que os alunos faziam de sua performance na expressão oral em PLE, respondidos pelos alunos no início e no fim do período de intervenção; b) transcrição dos simulados realizados pelos alunos; c) anotações no diário de campo da pesquisadora.

\section{Procedimentos de ANÁLISE dos Dados}

Para a análise dos dados, foram construídas grades contendo as seguintes categorias de análise: autoavaliação do desempenho, percepções do exame Celpe-Bras; estratégias de produção oral utilizadas, percepção dos instrumentos e das atividades, regulação de estratégias e métodos de estudo. Essas grades nos permitiram sistematizar os numerosos dados constituídos ao longo do estudo e verificar até que ponto as atividades e os instrumentos propostos influenciaram positivamente o desenvolvimento da habilidade oral dos alunos.

\section{ANÁLISE}

As atividades e os instrumentos propostos neste estudo tinham como fim, além de preparar aqueles alunos para o Celpe-Bras, promover tanto a conscientização em relação aos critérios utilizados 
pelos examinadores da parte oral quanto a sua apropriação. Para isso, era preciso diagnosticar a situação.

\section{DiAgNÓSTICO PRÉVIO}

Os dados recolhidos antes do início da intervenção, nos questionários aplicados aos estudantes, mostraram que, ao autoavaliarem sua produção oral, os aprendentes: a) superestimavam sua performance; b) autoavaliavam-se genericamente, e c) observavam apenas aspectos linguísticos de sua produção.

No que tange à apreciação de seu desempenho, no início do período, sistematizamos, no Gráfico 1 , as respostas dos alunos à questão "Como você avalia seu desempenho na produção oral em português?":

GráFico 1 - AutOAVALIAÇÃo INICIAL DO DESEMPENHO NA PRODUÇÃo ORAL

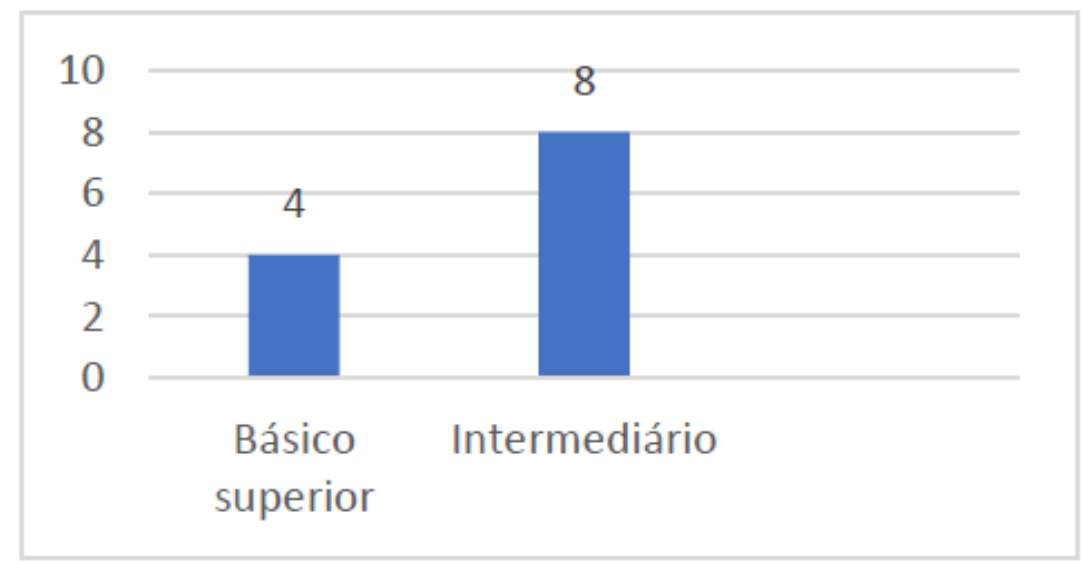

Fonte: Elaboração própria (2017)

O Gráfico 1 mostra que mais da metade dos aprendentes da turma apreciava seu desempenho como "básico superior" e "intermediário", níveis que não correspondiam à realidade, naquele momento, como mostra o Gráfico 2, construído com base no resultado do primeiro simulado realizado com a turma: 
Gráfico 2 - Resultados da AVALIAÇÃo DA PARTE ORAL NO PRIMEIRo SIMULADO

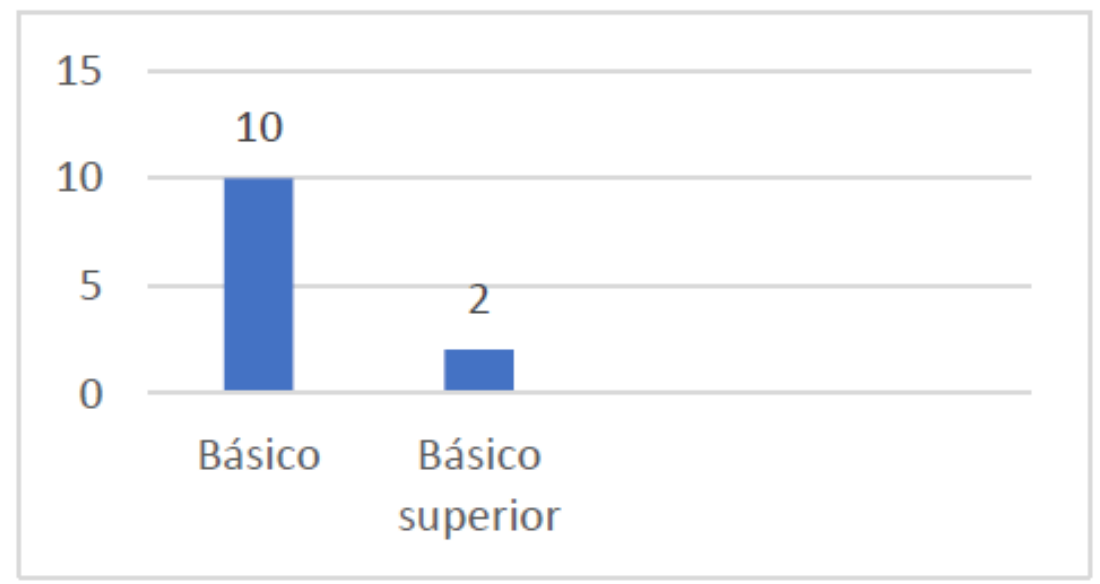

Fonte: Elaboração própria ( 2017)

Constatou-se, pois, inicialmente que os aprendentes faziam uma autoavaliação de seu desempenho bastante irrealista. As justificativas dadas por eles a respeito de seu desempenho confirmam a nossa hipótese de que eles consideravam já ter atingido o nível de proficiência necessário para o exame, por conseguir se comunicar em português em seu cotidiano. É o que muitos declaravam, como podemos perceber em todos os excetos abaixo, de (1) a (4):

(1) "Meu desempenho em português é bom por que hoje já consigo falar com brasileiros" (A3 - Questionário inicial).

(2) “[...] quando cheguei aqui no Brasil, eu não sabia nada de português, mas agora posso formular uma frase e conversar um pouco com brasileiros" (A7 - Questionário inicial).

(3) “[...] é intermediário por que eu não falo bem e também não falo ruim" (A9 - Questionário inicial).

(4) "[...] lembro quando cheguei aqui e não conseguia falar nada, mas agora falo e as pessoas também acham que eu falo bem" (A11 - Questionário inicial).

Além disso, percebemos que os aprendentes autoavaliavam seu desempenho de maneira genérica, em termos de "falar bem" e "falar 
corretamente", sem mencionar o que significaria cada uma dessas apreciações. Aqueles que se autoavaliavam menos superficialmente, em outras palavras, que durante a reflexão apontavam aspectos precisos em sua performance, citavam como critério de avaliação apenas a adequação gramatical, em especial o uso dos verbos em (5), (7), a velocidade da fala em (6) e a pronúncia em (8) e (9), como podemos observar nos depoimentos abaixo:

(1) “[...] Eu não me sinto satisfeito porque não chego formular bem uma frase, com o verbo, mesmo se eu conheço a resposta" (A2).

(1) "[...] Eu me sinto satisfeito, por que às vezes consigo falar muito rápido" (A4).

(1) "Não estou feliz com o meu desempenho por que [...] não falo português bom [...] eu não sei mais verbos" (A5).

(1) "Não estou satisfeito por que até o presente tenho uma pronuncia francesa e tenho muita dificuldade para formular corretamente uma frase" (A8).

(1) "Estou muito satisfeito por que agora eu posso pronunciar as palavras melhor" (A10).

Feito esse primeiro diagnóstico, foram implementadas atividades de construção dos critérios que foram usadas sistematicamente ao longo do período de preparação à parte oral do exame nos seis meses que o antecederam. Essa implementação foi uma estratégia para sensibilizarmos os aprendentes com relação a todos os critérios de avaliação da parte oral do Celpe-Bras, para que, posteriormente, fizessem uso deles na autoavaliação e na autorregulação de seu desempenho.

Os resultados obtidos, ao término do período desse trabalho de natureza formativa, foram organizados em três categorias, de modo a compreender melhor o alcance dos procedimentos implementados. São elas: a) Aumento da capacidade de autoavaliação; b) Regulação de hábitos/estratégias de estudo; c) Percepção dos instrumentos e atividades implementados.

As categorias supracitadas serão agora analisadas e discutidas uma a uma. 
Constatamos que houve uma nítida progressão de uma autoavaliação totalmente irrealista, apresentada no Gráfico 1, para uma autoavaliação mais condizente com a realidade, como podemos ver no Gráfico 3, referente à comparação entre a autoavaliação realizada pelos alunos ao fim da intervenção, às vésperas do exame, e a avaliação do simulado final feita pela professora:

Gráfico 3 - AutOAVALIAÇÃo FINAL: NÍVEIS DE DESEMPENHO ATRIBUídOS PELOS ALUNOS E PELA PROFESSORA

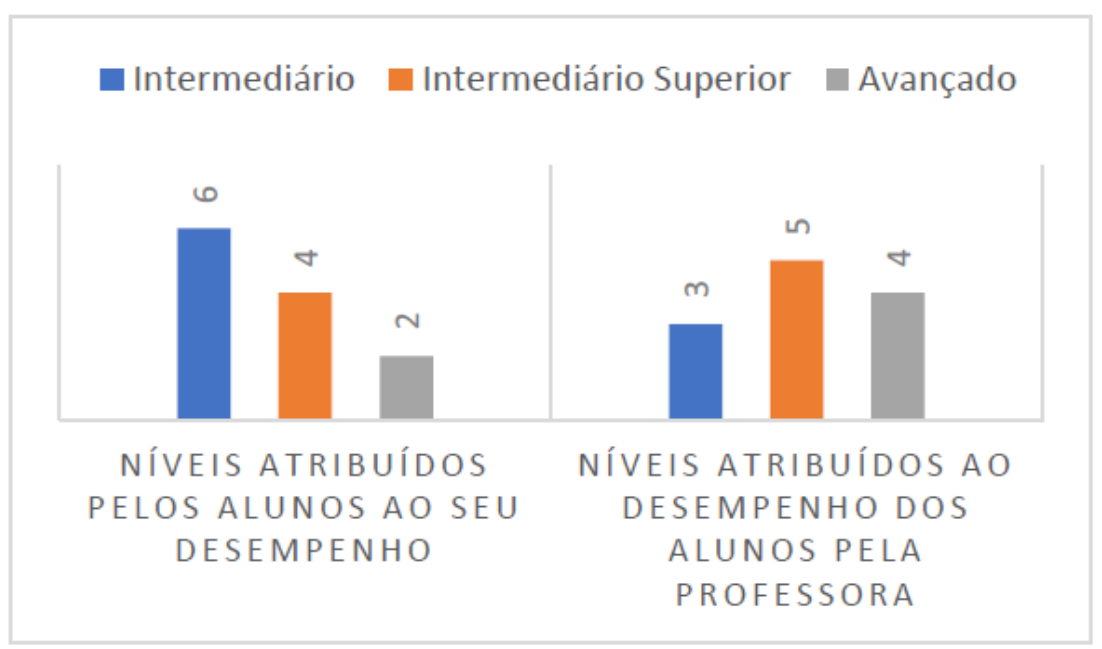

Fonte: Elaboração própria ( 2017).

Ao longo da intervenção, percebemos o incremento das capacidades autoavaliativas dos aprendentes, que passaram a explicitar, com a ajuda dos critérios de avaliação (como desenvolvimento da resposta, fluência, vocabulário, pronúncia), onde precisavam melhorar na produção oral, como podemos verificar nos trechos abaixo:

(11) “Já estou bem na pronúncia e na fluência, agora preciso melhorar o desenvolvimento da resposta ... falar mais, argumentar" (A4 - simulado 4). 
(12) “Eu acho que quando estou falando eu misturo a língua materna com o português no vocabulário e na pronúncia [...] e mais, o desenvolvimento da resposta por que não é só responder sim ou não. Tem que argumentar" (A7 - simulado 4).

(13) “"...] no início no meu primeiro simulado estava complicado. Eu não sabia como desenvolver a resposta, como entender o assunto, por que eu não conhecia as palavras... não tinha vocabulário e não sabia também como interagir com o entrevistador" (A8 - simulado 4).

(14)“[...] tenho que trabalhar mais o meu vocabulário eu não devo usar as mesmas palavras cada vez" (A12 simulado 4).

Constatamos que o trabalho com as grades de avaliação foi bem-sucedido, uma vez que despertou os alunos para as dimensões linguageiras de suas performances, isto é, para além dos aspectos linguísticos mencionados nas primeiras entrevistas e no questionário inicial. No momento do feedback, durante a entrega dos resultados, percebemos ao longo da intervenção que os alunos refletiam cada vez mais sobre o seu desempenho, não apenas no âmbito linguístico, mas também, e principalmente, no linguageiro.

Além da apropriação dos critérios de avaliação, observamos outro efeito positivo das intervenções, principalmente dos feedbacks realizados tanto individualmente quanto em grupo: a mudança de hábitos e de estratégias de estudo dos aprendentes, que discutiremos a seguir.

5.3 Regulação de hábitos e estratégias de estudo

Para averiguar de que maneira os aprendentes exercitavam a produção oral, incluímos nos questionários, inicial e final, a pergunta "Que atividades você realiza para treinar a produção oral fora de sala de aula?", cujas respostas estão sintetizadas no Gráfico 4. 
Gráfico 4 - EstratéGIAS DE PRODUÇão ORAL

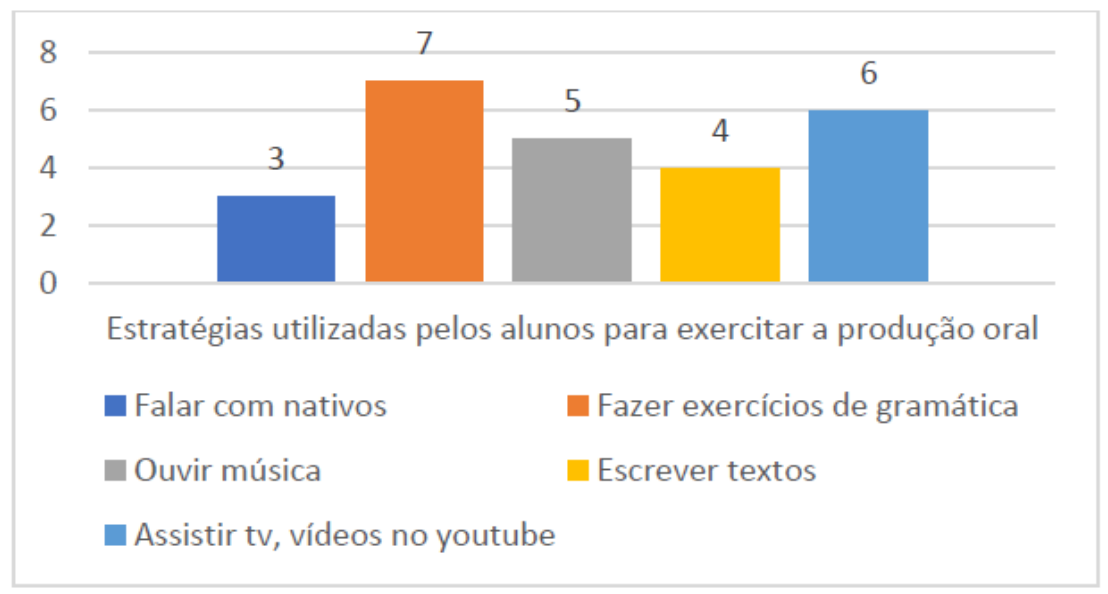

Fonte: Elaboração própria (2017)

Em suas respostas, os alunos diziam realizarmais de uma atividade, no entanto, não mencionavam que estratégias estavam mobilizando. Como podemos perceber nos excertos abaixo, simplesmente faziam as atividades:

(15) "Para treinar a produção oral fora da sala de aula, eu estudo muitos verbos, gramática e vocabulário" (A1 - Questionário inicial).

(16) “Vídeo, áudio, gramática" (A2 - Questionário inicial)

(17) “Às vezes eu assisto tv, escuto música e estudo os verbos” (A5 - Questionário inicial).

(18) "Eu falo com os meus amigos brasileiros e escrevo mensagens para eles também" (A6 - Questionário inicial).

(19) “Tenho só uma atividade para treinar a minha produção oral fora da sala de aula que é ouvir música" (A8 - Questionário inicial)

Por exemplo, eles poderiam assistir à tv, ouvir música, ouvir os áudios do livro, mas de maneira passiva, ou seja, sem tomar notas de expressões/palavras desconhecidas, sem reescutar os trechos que 
não haviam entendido, sem fazer, portanto, uma escuta mais atenta desses documentos. Com base nesses dados, foram realizados vários momentos de discussão sobre hábitos e estratégias de aprendizagem durante as aulas. Nas discussões, essas atividades eram realizadas de duas maneiras:

a. Os alunos explicitavam suas estratégias (ex: assistir a séries) e a professora buscava, por meio de questionamentos, conhecer como eles realizavam a atividade (ex: você assiste a série em português? Como, dublado ou legendado? O que você faz enquanto assiste a série? Você anota novas palavras/ expressões?) para então sugerir métodos de realização mais adequados para o desenvolvimento da produção oral (ex: escolher séries de que você goste e que tenham episódios curtos; assistir três vezes - a primeira dublada, a segunda legendada e a terceira em português sem legenda; anotar palavras/expressões novas e usá-las em seu dia a dia);

b. A professora realizava a estratégia em conjunto com os alunos e, ao fim da atividade, explicitava-a e incitava-os a reutilizá-las com autonomia (ex: assistir a um vídeo trechos de jornais, de novelas, vídeo do YouTube - fazendo anotações para, posteriormente, discutir sobre o tema com os colegas da sala, argumentar a favor ou contra...).

c. Os dados oriundos do questionário final apontam para o incremento de estratégias voltadas para a produção oral, como vemos no Gráfico 5: 
Gráfico 5 - ESTRatÉGIAS DE PRODUÇão ORAL

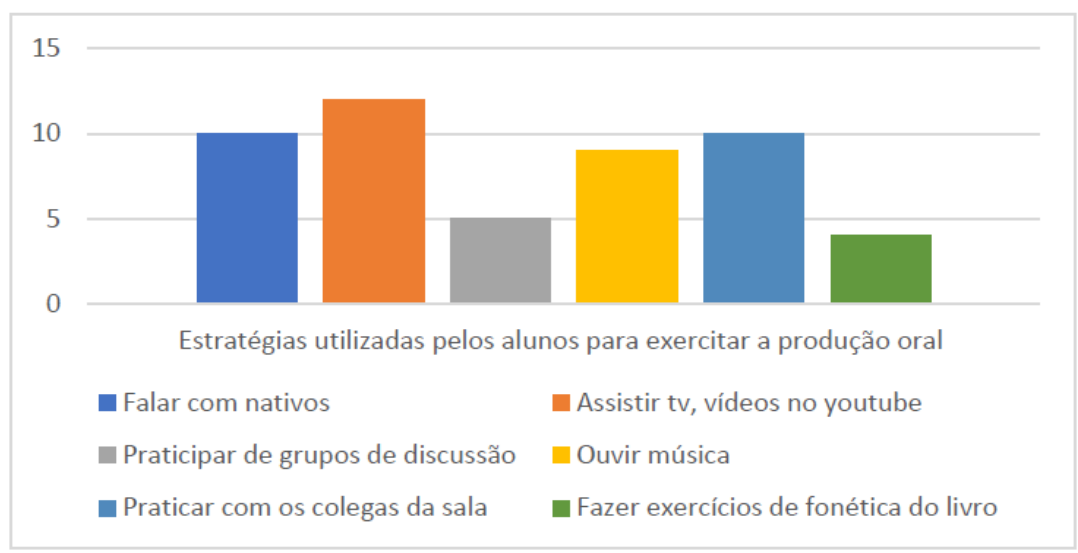

Fonte: Elaboração própria (2017)

Percebemos uma ampliação significativa do leque de estratégias voltadas para a interação, seja com nativos, seja com os colegas da sala, bem como a adoção de novas estratégias, como fazer exercícios de fonética do livro e participar de grupos de discussão - principalmente nas igrejas que os alunos frequentam. Também constatamos que, em suas justificativas, os aprendentes demonstravam utilizar as estratégias de maneira mais consciente e ativa:

(20) "Eu realizo atividade como ouvir a música, procurar a letra, tentar cantar junto, praticar a conversa com meus amigos brasileiros em português, só em português, consulto os livros, assistir o jornal, anotar os assuntos e conversar depois" (A1 - Questionário final).

(21) “[...] eu sempre assisto filmes, leio para eu pegar novas palavras e saio para praticá-las com minhas amigas" (A3 Questionário final).

(22) "Fora da sala de aula, gosto de ouvir música, falar com meus amigos em português, assistir a televisão e filme e sempre procurar coisas novas que eu nunca ouvi para pesquisar e usar. Também sempre no ônibus presto atenção sobre as palavras das pessoas para conseguir imitar o sotaque deles" (A6 - Questionário final). 
(23) “[...] eu sempre tento conversar em português com meus amigos, os brasileiros, ver as reportagens e falar com eles, saber a opinião e depois eles me corrigem qualquer atividade que eu faço, sempre quero me comunicar em português. A música também me ajuda muito para a pronúncia" (A8 Questionário final).

(24) "Eu assisto filmes e séries em português, como a professora disse. Eu leio livros em português, revistas e falo com os meus amigos depois do que eu li, falo muito com nativos da língua e peço pra me corrigir" (A10 - Questionário final).

Consideramos que as atividades de explicitação/utilização de estratégias foram muito frutíferas, principalmente por despertar os alunos para o fato de que, no contexto em que se encontram, o leque de possibilidades de praticar/aprender a língua, especialmente no que tange à produção oral, é bem amplo. Perceberam que a aprendizagem do português pode se estender para além das paredes da sala de aula e que atividades cotidianas como assistir à televisão e ouvir música também são oportunidades de aprendizagem.

\section{PeRCEPÇÕES dos InSTRUMENTOS E ATIVIDAdes IMPLEMENTAdos}

Ainda com o objetivo de conhecer os efeitos dos procedimentos e instrumentos implementados, procuramos saber, junto aos alunos, em que medida as atividades de avaliação e os simulados realizados teriam contribuído para a preparação da parte oral do exame Celpe-Bras.

De acordo com as respostas obtidas na questão "Os simulados realizados nas aulas de produção oral contribuíram para a melhoria da sua aprendizagem do português? Como?", percebemos que os simulados foram especialmente proveitosos porque, ao colocar os alunos em situações semelhantes àquelas que encontrariam no dia do exame, contribuíram para a conscientização das suas reais exigências, como declararam em diversas oportunidades:

(25) "Sim. Contribuíram para melhoria porque são mesma coisa vou fazer no Celpe-Bras e me deram confiança” (A4 Questionário final). 
(26) "Contribuiu muito por que cada vez que tem um assunto você tem que fazer pesquisa pra compreender o que este assunto quer dizer; cada vez que eu recebo esse elemento provocador eu tento de compreender o que o assunto quer dizer" (A7 - Simulado final).

(27) “Sim, muito [...] acho que se eu não tivesse feito esses simulados eu não chegaria no lugar onde eu estou [...] e esses simulados oral na aula me ajudam muito por que às vezes eu não sei como analisar um elemento e os professores me ajudando e agora eu estou mais confortável com esses elementos e eu posso analisar eles muito bem e eu não tenho medo mais de fazer essa prova, na primeira vez eu tinha muito" (A10 - Simulado final).

(28) "Sim, muito muito por que primeiro isso me permite de saber como será o dia da prova, por que ainda não sabemos o que íamos enfrentar no dia; além disso isso me permite também de conhecer os elementos provocadores" (A12 Simulado final).

Constatamos que, além de desconstruir a crença de que conseguir se comunicar em português fora de sala é suficiente para obter o nível mínimo no Celpe-Bras, os simulados contribuem positivamente para o aumento da autoestima e da segurança do aprendente na hora do exame.

Outra dimensão significativa do trabalho com os simulados foi o uso das grades com os critérios de avaliação da parte oral, não só pelo professor, mas pelos próprios aprendentes em atividades de avaliação mútua. Ao serem perguntados acerca do impacto desses instrumentos na melhoria de sua aprendizagem, os alunos testemunhavam que, ao avaliar a produção dos colegas, após as tarefas, conseguiam perceber com mais facilidade os erros que cometiam quando detectavam os mesmos problemas nas produções dos parceiros. Segundo os alunos, essas atividades foram importantes na conscientização de que aspectos precisavam melhorar:

(29) “A avaliação está ajudando bastante por que quando você está aprendendo alguma coisa você precisa avaliar para saber o nível onde você já chegou, por que se não tem 
avaliação você não vai saber como você está evoluindo em alguma coisa que você está fazendo. Então, pra mim a avaliação está ajudando muito por que permite ameliorar sobre alguma coisa" (A1 - Simulado final).

(30) "Contribuiu muito por que quando você por exemplo viu que você está estagnado no mesmo lugar você vai ter vontade de trabalhar muito algo que você deseja, seja melhorar seu jeito de trabalhar para melhorar, melhorar até você vai conseguir um jeito que vai contribuir com a sua aprendizagem" (A3 Simulado final).

(31) "Sim estão me ajudando muito [...] indica que eu estou melhorando e semana passada fizemos uma entrevista e quando saí eu vi que não desenvolvi muito a resposta eu achei que semana passada eu tinha intermediário, mas agora tenho intermediário superior isso significa que eu já melhorei. Ainda estou melhorando: eu quero alcançar o meu sonho para chegar no avançado eu acho no fim do mês eu vou chegar lá" (A4 - Simulado final)

(32) "Sim contribuiu, por que as grades têm diferentes espaços, fluência, pronúncia [...] por que eu posso ver cada etapa eu posso entender o que eu devo fazer para melhorar e eu sei em qual área eu estou bem e em qual área eu ainda devo melhorar" (A10 - Simulado final).

Como podemos verificar nos depoimentos acima, conhecer o seu nível efetivo de proficiência em diversos aspectos da língua, longe de levar os alunos ao desânimo, quando os resultados não eram tão bons quanto esperavam, os motivaram a se esforçar mais para obter resultados melhores.

A análise dos dados revela, portanto, que os instrumentos e os procedimentos implementados surtiram efeitos positivos na desconstrução de uma compreensão equivocada das exigências do exame e do nível de proficiência dos alunos, bem como na adoção de estratégias de aprendizagem mais adequadas para o desenvolvimento da produção oral. Esse efeito foi comprovado, posteriormente, pelos resultados obtidos no exame, ${ }^{5}$ quando todos obtiveram êxito com classificação "Intermediário" para nove dentre eles e "Intermediário Superior" para três. 


\section{Conclusẽo}

Este estudo teve como objetivo sistematizar e analisar parte dos numerosos dados produzidos ao longo de uma intervenção implementada em uma turma de pré-PEC-G da UFPA. A experiência visava promover a apropriação dos critérios de avaliação da parte oral do Celpe-Bras, com o intuito de melhor preparar os aprendentes para o referido exame, fomentando suas capacidades autoavaliativas.

Com base nos resultados obtidos, percebe-se claramente que a avaliação formativa vai bem além da mera atribuição de níveis e de notas. $\mathrm{O}$ impacto primeiro causado pela apropriação dos critérios de avaliação incide no desempenho comunicativo dos aprendentes, que, conforme vão conseguindo se comunicar de maneira eficaz em português, também passam a enxergar melhor, nas produções dos seus pares e em suas próprias, indicadores de que esses critérios estão sendo atendidos ou não. A sua capacidade de (auto)avaliação assim incrementada orienta-os quanto ao rumo que seus esforços devem tomar para se expressar de maneira adequada. Como resultado, temse, em poucos meses, uma grande melhoria do "produto linguageiro", quando todos alcançam classificações Intermediário ou Intermediário Superior, o que contrasta com os resultados apurados inicialmente pela professora (ver Gráfico 2), em que nenhum dos envolvidos conseguiria aprovação.

O segundo nível de impacto está relacionado não apenas com o produto, mas também com o processo de aprendizagem. A avaliação formativa não se limita a possibilitar um incremento dos produtos esperados, no ensino da língua, mas, como já ressaltamos, sua natureza metacognitiva torna possível uma reflexão - e uma ação - a respeito do modo como se aprende. A regulação não é mais apenas regulação da comunicação, do modo como cada um realiza a atividade linguageira proposta, mas se torna também regulação da aprendizagem, do modo como cada um passa a estudar, de forma mais consciente e intencional, ao praticar diversas ações do cotidiano (assistir à tv, ouvir as pessoas se comunicarem no ônibus etc.). De fato, paulatinamente, os aprendentes passaram não apenas a adotar estratégias de estudo mais produtivas para o desenvolvimento das suas competências orais, mas também ampliaram o leque de estratégias que já utilizavam. 
Concluímos que, no contexto de preparação para o Celpe-Bras, proporcionar aos alunos momentos de aprendizagem/uso da língua portuguesa atrelados a atividades de reflexão sobre os critérios de avaliação de seu desempenho e de regulação desse desempenho é um fator decisivo para a mudança da percepção daquilo que é esperado deles no exame e, principalmente, para a mudança de atitude no que diz respeito ao seu modo de estudar e à maneira de apreciar seu desempenho, o que, sem dúvida, permite-lhes continuar a desenvolver suas competências linguageiras em português, mesmo depois de encerrado o curso.

De um modo mais amplo, pode-se afirmar que os resultados obtidos reforçam a pertinência da integração dos pressupostos da avaliação formativa no contexto de ensino/aprendizagem de PLE.

FORMATIVE ASSESSMENT IN ORAL PRODUCTION: ANALYSIS OF AN EXPerience in a COURSe of Portuguese Foreign Language

\begin{abstract}
This work investigates the impact of formative evaluation procedures in the development of oral production competence in learners of Portuguese Foreign Language. We sought to determine how the appropriation of the oral evaluation criteria used in the Portuguese Language Proficiency Certificate exam contributes to the development of this ability in students preparing for the exam. The results of the action research analyzed here reveal that the implemented actions have enabled not only self-assessment practices that are more consistent with each criteria, but also the self-regulation of learning methods and strategies, leading students to a better level of preparation for the exam.
\end{abstract}

KEYWORDS: formative evaluation, self-regulation of learning, oral production, Portuguese Foreign Language, Celpe-Bras Exam.

EVALUACIÓN FORMATIVA EN LA PRODUCCIÓN ORAL: ANÁLISIS DE UNA EXPERIENCIA EN UN CURSO DE PoRTugués Lengua EXTRANJERA

\title{
RESUMEN
}

Este trabajo investigó el impacto de procedimientos de evaluación formativa en el desarrollo de la competencia de producción oral en alumnos de Portugués 
Lengua Extranjera. A través de cuestionarios y entrevistas, se averiguó de qué manera la apropiación de criterios de evaluación de la producción oral, usados en el examen del Certificado de Suficiencia de la Lengua Portuguesa (Celpe-Bras), contribuyen con el desarrollo de esa habilidad en alumnos que se preparan para el Celpe-Bras. Los resultados de la investigación-acción desarrollada revelaron que las acciones efectuadas posibilitaron, no solamente prácticas auto evaluativas más acordes con cada criterio, como también autoregulación de métodos y estrategias de aprendizaje, mejorando el nivel de preparación de esos estudiantes.

Palabras Clave: evaluación formativa, autorregulación del aprendizaje, producción oral, Portugués Lengua Extranjera, Examen Celpe-Bras.

\section{NotAS}

1. Para Barbot (2000, p.135): "a autoavaliação confere o lugar central à aquisição de estratégias [...] essa aquisição garantirá ao aprendiz o que David Little designava recentemente como 'competência estratégica', diretamente ligada à aquisição da competência de aprendizagem (aprender a aprender), designada agora como domínio estratégico".

2. Os elementos provocadores são materiais impressos com conteúdo verbal e não verbal, retirados de fontes variadas (como revistas, jornais, outdoor, folhetos, fotos etc.) e pertencentes a gêneros diversos (como infográfico, anúncio publicitário, charge, cartum, lide de artigo, artigo curto etc.).

3. Todos os participantes assinaram um Termo de Consentimento Livre e Esclarecido.

4. A presente pesquisa foi realizada em conformidade com as orientações institucionais da Universidade Federal do Pará.

5. Informação comunicada pela coordenação do curso.

\section{REFERÊNCIAS}

ALLAL, Linda. Stratégies d'évaluation formative: conceptions psychopédagogiques et modalités d'application. In: ALLAL, Linda; CARDINET, 
Jean; PERRENOUD, Philippe (Org.). L'évaluation formative dans un enseignement différencié. Berne: Peter Lang, 1989. p. 153-183.

ALLAL, Linda; MICHEL, Yviane. Autoévaluation et évaluation mutuelle en situation de production écrite. In: ALLAL, Linda; BAIN, Daniel; PERRENOUD, Philippe (Org.). Évaluation formative et didactique $d u$ français. Paris: Delachaux \& Niestlé, 1993. p. 239-267.

BARBOT, Marie-José. Un premier rôle pour l'évaluation sur la scène de la didactique? Mélanges CRAPEL, n. 25, p. 129-151, 2000.

BONNIOL, Jean-Jacques; VIAL, Michel. Les modèles de l'évaluation : textes fondateurs avec commentaires. Bruxelles: De Bœck, 1997.

BRASIL. Ministério das Relações Exteriores. Divisão de Temas Educacionais. Programa de Estudantes-Convênio de Graduação - PEC-G. Apresentação. S/d. Disponível em <http://www.dce.mre.gov.br/PEC/PECG.php.>. Acesso em: 2 fev. 2017

ENGEL, Guido Irineu. Pesquisa-ação. Educar, Curitiba, n. 16, p. 181-191, 2000 .

FERNANDES, Domingos. Para uma teoria da avaliação no domínio das aprendizagens. Estudos em avaliação educacional, São Paulo, v. 19, n. 41, p. 347-372, set./dez. 2008.

- Vinte e cinco anos de avaliação das aprendizagens: uma síntese interpretativa de artigos publicados em Portugal. Revista Portuguesa de Pedagogia, v. 40, n. 3, p. 289-348, 2006.

GREGO, Sonia Maria Duarte. A Avaliação Formativa: ressignificando concepções e processos. In: UNIVERSIDADE ESTADUAL PAULISTA, Pró-Reitoria de Graduação. (Org.). Caderno de Formação: Formação de Professores, Avaliação Educacional e Escolar. São Paulo: Cultura Acadêmica: UNESP, Pró-Reitoria de Graduação, 2013. p. 92-110.

HOFFMANN, Jussara. Avaliar para promover: as setas do caminho. Porto Alegre: Ed.Mediação, 2005.

HUVER, Emmanuelle; SPRINGER, Claude. L'évaluation en langues. Paris: Didier, 2011.

INEP. Instituto Nacional de Estudos e Pesquisas Educacionais Anisio Teixeira Certificado de Proficiência de Língua Portuguesa para Estrangeiros: Manual do candidato 2011. Disponível em: <http://celpebras.inep.gov.br/inscricao/ manual/manualCandidato.pdf.>. Acesso em: 18 fev. 2017. 
LEROY, Henrique Rodrigues. Interculturalidade e avaliação em LínguaCultura Portuguesa para Estrangeiros: a competência intercultural no exame Celpe-Bras. In: DELL'ISOLA, Regina L. Péret (Org.). O exame de proficiência Celpe-Bras em foco. São Paulo: Pontes, 2014. p. 55-67.

MELO, Kelly C. Marigliani. Modalidades de avaliação da aprendizagem e suas relações com o ensino/aprendizagem de Português Língua Materna. 2009. 120 f. Dissertação (Mestrado em Letras - Estudos Linguísticos) - Instituto de Letras e Comunicação, Universidade Federal do Pará, Belém, 2009.

MOUTINHO, Ricardo; VIANA, Nelson. O efeito retroativo exercido pelo Celpe-Bras: considerações sobre os impactos provocados por um exame de proficiência de natureza comunicativa. In: SILVA, Kleber Aparecido (Org.). Crenças, discurso e linguagem. Campinas: Pontes, 2011.

NUNZIATI, Georgette. Pour construire un dispositif d'évaluation formatrice. Cahiers Pédagogiques, Paris, n. 208, p. 47- 64, jan. 1990.

PERRENOUD, Philippe. L'évaluation des élèves: de la fabrication de l'excellence à la régulation des apprentissages. Paris: De Boeck, 1998.

PILLONEL, Marlyse; ROUILLER, Jean. Faire appel à l'auto-évaluation pour développer l'autonomie de l'apprenant. Résonances, v.7, p. 28-31, 2002.

Submetido em 01 de dezembro de 2017

Aceito em 01 de março de 2018

Publicado 30 de novembro de 2018 